\title{
Evidências Científicas e Análise Comparada de Programas de rastreamento: Elementos para Discussão das Condições Essenciais para o rastreamento Organizado do Câncer de Mama no Brasil
}

Scientific Evidences and Comparative Analysis of screening Programs: Elements for Discussion of the Essential Conditions for Organized Breast Cancer screening in Brazil

Las Evidencias Científicas y Análisis Comparado de Programas de rastreo: Elementos para la Discusión de las Condiciones Esenciales para el rastreo Organizado del Cáncer de Mama en Brasil

\author{
Ronaldo Corrêa Ferreira da Silva ${ }^{1}$; Virginia Alonso Hortale ${ }^{2}$
}

\section{Resumo}

Introduçáo: $\mathrm{O}$ câncer de mama é um problema de saúde pública nos países em desenvolvimento em razão do envelhecimento da populaçáo, do aumento dos fatores de risco e pela dificuldade dos sistemas de saúde em desempenhar suas funçôes e objetivos. Objetivo: Demonstrar como as evidências científicas e a análise comparada de programas de rastreamento do câncer de mama podem contribuir para identificar elementos para contextualizar o rastreamento organizado do câncer de mama no Brasil. Método: Com base no referencial teórico sobre a utilização das evidências científicas na elaboração de políticas e programas de saúde, analisam-se as evidências sobre o rastreamento do câncer de mama, e realizou-se uma análise comparada dos sistemas de saúde e programas de rastreamento mamográfico na Inglaterra e província de Ontário no Canadá. Resultados: Há alguns anos, os países desenvolvidos implantaram programas de rastreamento do câncer de mama e hoje apresentam reduçôes importantes da sua mortalidade. Os programas de rastreamento são intervençôes complexas que demandam sistemas de saúde bem estruturados em diferentes contextos e dimensões. Esses países implementaram estratégias de monitoramento e avaliação sistemática de seus programas de rastreamento para garantir que os benefícios superassem os possíveis malefícios. Os países em desenvolvimento carecem de evidências de que os benefícios superam os malefícios e ainda não aprimoraram seus sistemas de saúde de modo a implantar programas de rastreamento efetivos e seguros. Conclusão: A análise dos programas e as evidências científicas permitiram identificar 17 elementos essenciais para contextualizar o rastreamento organizado do câncer de mama no Brasil.

Palavras-chave: Neoplasias da Mama; Neoplasias da Mama-prevenção \& controle; Programas de Rastreamento-estatística e dados numéricos; Saúde Pública

Tese apresentada no Programa de Pós-Graduação em Saúde Pública da Escola Nacional de Saúde Pública Sergio Arouca. Fundação Oswaldo Cruz (ENSP/Fiocruz) com vistas à obtenção do título de Doutor em Ciências na Área de Saúde Pública.

${ }^{1}$ Médico-Oncologista Clínico e Sanitarista da Divisão de Apoio à Rede de Atenção Oncológica do Instituto Nacional de Câncer José Alencar Gomes da Silva (DARAO/INCA). Doutor em Saúde Pública pela ENSP/Fiocruz. Rio de Janeiro (RJ), Brasil.

${ }^{2}$ Professora. Doutora da ENSP/Fiocruz. Rio de Janeiro (RJ), Brasil. Orientadora.

Endereço para correspondência: Ronaldo Corrêa Ferreira da Silva. Serviço de Qualidade em Radiaçóes Ionizantes (SQRI)/DARAO/INCA. Rua do Resende, 128 - sala 322 - Centro. Rio de Janeiro (RJ), Brasil. CEP: 20231-092.E-mail: rsilva@inca.gov.br. 